\title{
SELECTION PROCEDURE OF NUMBER OF PLIES FOR CARBON FIBER TIE RODSFOR ALL TERRAIN VEHICLE
}

\author{
Omkar Diliprao Suryavanshi ${ }^{1}$ \\ ${ }^{1}$ Student, Department of Mechanical, Vishwakarma Institute of Technology, Maharashtra, India
}

\begin{abstract}
Tie rod is a mechanical linkage which connects the steering gear box to the steering knuckle joint. It is also one of the major weight contributing component in the steering system. To reduce the weight of the tie rods several attempts has been made by using composite materials like carbon fibre for designing and manufacturing of the tie rods. However Strength of composite material changes depending upon number of plies in particular direction. This paper aims to provide guideline for selection of plies for carben fibre composite and analyse the effects of ply orientation on strength of composite tie rod. Structural analysis of the tie rod is carried out by using ANSYS software and results are compared with maximum permissible value of stress and deformation to ensure that designed Designed composite tie rod is safe.
\end{abstract}

Keywords: - Ply orientation, ANSYS, Carbon Fiber, Von- Mises Stress -- ***

\section{INTRODUCTION [1]}

Tie rod or track rod is the important link in the steering subsystem. Steering system is generally divided into two subsystems. First consists of steering wheel, steering column, and universal joint while other consists of the tie rods, steering arms and other steering linkages which converts rotational motion from steering wheel into linear motion by using steering gearbox and transfers linear force to turn the wheel. Tie rod of Steering system connects center link to the steering knuckle in conventional suspension system and rack to the steering knuckle in McPherson suspension system. Tie rod generally gets force from rack and transfer it to the steering knuckle to turn the wheels The basic function of steering mechanism is to turn the wheels about a pivot point. Therefore there should not be rigid construction between mechanisms. Spherical ball joints or the rod ends are used to provide degree of freedom to the linkages in all three planes.. Tie rod is a circular rod with threaded part, Outer end and inner end. Tie rod is mostly made up of alloy steel. As due to advances in technology and popularity of the composite material now a days it becomes common to use composite materials like carbon fibre for the automobile purpose like drive shaft, steering wheel, tie rods, body panels etc. due to increase in demand for the lightweight material in racing cars or high speed vehicles which helps to gain maximum fuel economy with increased speed it becomes necessary to replace dense material like steel with light weight composite materials which successfully performs all the necessary function and helps to reduce the overall weight of the vehicle. Carbon fiber reinforced composite is the excellent alternative for this application. In this composite carbon fibers are the load bearing components. Due to their low density, high strength and high modulus of elasticity they offer significant weight reduction potential. The main objective of this paper is to explain design methodology for carbon fiber tie rods for all- terrain vehicle and to validate the feasibility of the design by using finite element analysis using ANSYS.

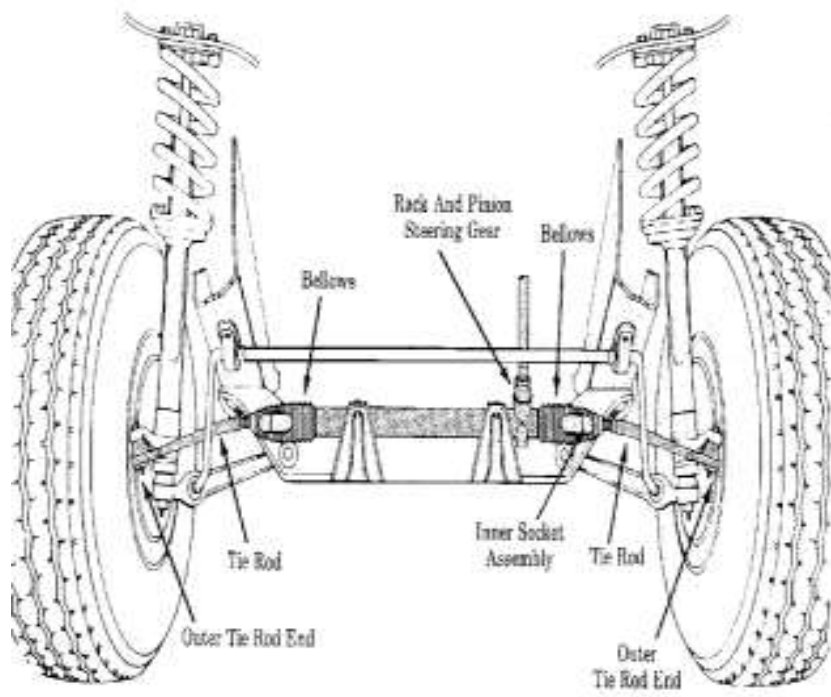

Fig 1: steering subsystem components

\section{COMPOSITE MATERIAL [2]}

In the classical process of conception or design there are constraint over a modification in the properties of a material. Since we have to select an existing isotropic material and design our component according to the properties of that material. While this template doesn't apply for composite material. In composite material the design has freedom to select or create a material according to functional requirements just by altering the reinforcement, the matrix and the process of curing. Hence you can use the same material for altogether different applications just by changing orientation of fibers and the process of curing. 
Safety factor for composite materials [4] - strength of composite material varies depending upon the type of loading and the duration of the loading hence it is necessary to introduce different safety factor for different types of loading. Stress concentration plays important role in deciding the magnitude of safety factor for the laminate. For example if there is rapid change in cross section area or if during the fabrication process the fibres are not bound together properly, then the probability of failure of laminate increases. However this type of failure is the first ply failure and the laminate can still be used for the application up to the ultimate failure, it is usually designer's decision whether to use the laminate or to discard it. As the composite material gets used for the long time some defects may be produced in that material which decreases its overall strength. Therefore to take care of all these uncertainties safety factor is introduced as follows into the two main characteristics -1.High volume composites, 2.High performance composites

High volume composites is again divided depending upon type of loading and the type of duration as follows-

Table 1: Type of composites and their Factor of safety

\begin{tabular}{|l|l|l|l|}
\hline SR NO & Type & Sub-Type & FOS \\
\hline 1 & $\begin{array}{l}\text { High } \\
\text { volume } \\
\text { composites }\end{array}$ & Static loading & \\
\hline 1.1 & & Short duration & 2 \\
\hline 1.11 & & Long duration & 4 \\
\hline 1.12 & & $\begin{array}{l}\text { Intermittent } \\
\text { loading over } \\
\text { long term }\end{array}$ & 4 \\
\hline 1.2 & & Cyclic loading & 5 \\
\hline 1.3 & & Impact loading & 10 \\
\hline 1.4 & $\begin{array}{l}\text { High } \\
\text { performance } \\
\text { composites }\end{array}$ & & 1.3 to 1.8 \\
\hline 2 & & \\
\hline
\end{tabular}

From the chart we can conclude that composite material may not be suitable for the impact loading application since factor of safety is very high.

\section{FORCES ON TIE RODS [1]}

Before designing the laminate sheet of carbon fiber with percentage orientation of the fiber in each direction it is necessary to evaluate types of forces acting on the tie rod and the nature of the forces. We can decide the fiber orientation for laminate only by finding out direction in which tie rod has most probability to fail and nature of forces. Since tie rod is the steering linkage which connects the steering gear box (rack and pinion) to the steering arm. Ball joint or the rod ends are used to transfer the moment from gear box to the wheels since there is obliquity in the plane of steering gear box and the tie rods. Torque applied at the steering wheel is transferred through steering column towards the steering gear box. Generally rack and pinion gear box is used for this arrangement because of simplest construction and less moving parts. Sometimes universal joint is used to connect steering column to the gear box. In this case we have to consider the efficiency of the universal joint. The steering gearbox converts rotary motion into linear motion which is then transferred through tie rods towards wheel. Force on the rack is the pinion torque multiplied by the pinion radius. Since tie rods and rack are connect to each other by means of rod ends we can get force on tie rods by calculating angle between tie rods and rack. Nature of the force is tensile.

\section{IMPORTANCE OF PLY ORIENTATION [3]}

Although unidirectional layers have high rigidity and the load transmission is continuous over a large distance, to cover a complex shape one cannot use unidirectional ply. Also the time of wrapping is long in case of unidirectional ply. Hence there is a need to design laminate which have multiple layers of different orientation which can produce complex shapes using deformation of the fabric. Unlike the glass epoxy material carbon fiber is an anisotropic type of material. I.e. its properties are not constant. It changes with change in the direction of the fiber. Hence ability to resist the loading varies depending upon the percentage orientation of the plies in each direction.

\subsection{Carbon Epoxy Laminates [2]}

To design a carbon fiber sheet, minimum percentage of plies in any direction must be $10 \%$. Since the nature of the force transmitted from the steering gearbox to the tie rod is tensile it is necessary to have maximum number of plies in the direction parallel to the applied force. However when the vehicle is in dynamic condition several unpredictable forces may be arises due to the bumps on the road, forces during cornering, forces due to normal component of overall weight on steered axle or the transmission of tractive force during acceleration. These forces acts in a plane different than that of longitudinal plane along which tensile force is acting. Hence to avoid the failure of ply in these direction a minimum $10 \%$ of plies should be allotted in lateral planes as well as in the inclined planes. The composition of the carbon epoxy laminate is as follows-

Ply thickness $=0.13 \mathrm{~mm}$

From the book of composite materials design application table 5.1 we get maximum permissible value of stress in tension and compression for $60 \%$ volume fraction and 0.13 mm ply thickness.

Maximum permissible stress in $\mathrm{x}$ direction for above percentage of plies is

$6 \mathrm{xmax}$

Tension $=632 \mathrm{Mpa}$

Compression $=846 \mathrm{Mpa}$ 
Maximum permissible stress in $\mathrm{y}$ direction for above percentage of plies is

6 ymax

Tension $=157 \mathrm{Mpa}$

Compression $=217 \mathrm{Mpa}$

Maximum permissible shear stress for above percentage of plies is

Txymax $=118 \mathrm{Mpa}$

Modulus of elasticity EX $=100590 \mathrm{Mpa}$

Poisson's ratio $=0.29$

\section{CAlCulation [5]}

Now, to calculate the number of plies we need to equate the maximum permissible tensile stress in $\mathrm{x}$ direction to the maximum force applied on tie rod divided by the cross sectional area of tie rod.

To calculate the maximum force applied on the tie rod we need to calculate maximum torque at the steering wheel.

Maximum torque at the steering wheel $=100 \mathrm{Nm}[6]$

Assuming $100 \%$ efficiency same torque will be transmitted along the pinion gear.

Force on the pinion gear $=\frac{\text { Torque on pinion gear }}{\text { pinion radius }}$

Pinion radius $=0.013125 \mathrm{~m}$

Force on the pinion gear $=7619.04 \mathrm{~N}$

Force on the rack gear $=$ force on the pinion gear

Hence force on the rack gear $=7619.04 \mathrm{~N}$

Force on tie $\operatorname{rod}=\frac{\text { force on rack gear }}{\cos (\text { angle between rack and tie rod })}$

Angle between rack and tie rod $=19.98$ degree

Force on tie rod $=\frac{7619.04}{\cos (19.98)}$

Force on the tie $\operatorname{rod}=8106.98 \mathrm{~N}$

Table 2: percentage of ply in particular orientation [2]

\begin{tabular}{|l|l|l|}
\hline SR NO & $\begin{array}{l}\text { Percentage of } \\
\text { plies }\end{array}$ & $\begin{array}{l}\text { Orientation } \\
\text { degrees) }\end{array}$ \\
\hline 1 & $70 \%$ & 0 degree \\
\hline 2 & $10 \%$ & 90 degree \\
\hline 3 & $10 \%$ & 45 degree \\
\hline 4 & $10 \%$ & -45 degree \\
\hline
\end{tabular}

Since we are using high volume composite for cyclic load application we have to introduce the factor of safety for cyclic loading

$\mathrm{FOS}=5$

$$
\begin{gathered}
\frac{\text { Exmax }}{\text { FOS }}=\frac{\text { tensile force }}{\text { cross section area }} \\
\frac{632}{5}=\frac{8106.98}{n\left(R^{2}-r^{2}\right)}
\end{gathered}
$$

Where $\mathrm{R}=$ outer diameter of tie rod $\mathrm{r}=$ inner diameter of tie rod

Now inner diameter of tie rod $=$ outer diameter of insert $=$ $14 \mathrm{~mm}$

From that we get outer diameter of tie rod $=16.6632 \mathrm{~mm}$

Therefore thickness $=1.331602 \mathrm{~mm}$

Number of plies $=\frac{\text { Thickness of tie rod }}{\text { thickness of each ply }}$

$$
\begin{aligned}
& =\frac{1.3316}{0.13} \\
& =10.24
\end{aligned}
$$

Therefore total no of plies should be 11

Number of plies in each direction can be calculated by multiplying percentage number of plies by total no of plies.

In 0 degree direction $=70 \%=0.7 * 11=7.7$

Since number of plies must be whole number hence we have to approximate the value to nearest whole number

Therefore no of plies in 0 degree direction $=8$

Similarly no of plies in 90 degree direction $=1$

No of plies in 45degree direction $=1$

No of plies in -45 degree direction $=1$

Once the no of plies in each direction are determined next step is the analysis of the designed laminate to verify the enduring capability against the external dynamic forces.

\section{STRUCTURAL ANALYSIS OF TIE ROD}

In structural analysis of tie rod we have to analyse whether the tie rod has sufficient strength to withstand tensile forces generated during steering of vehicle. For the analysis of tie rod we have used the ANSYS software. For the analysis of any component there are three stages -1 . Pre-processing 2 . Solver 3. Post- processing. In pre- processing we have to give input parameter related to the geometry of component 
and material of component. We can create geometry in ANSYS software itself or we can import it from modeling software like CATIA. For the material selection you can choose standard material like stainless steel, Aluminium from the material library or you can create your own required material by editing density and ultimate tensile strrength and other physical parameters. For carben fibre material we create material in ANSYS library by adding material properties at particular ply orientation. Next step in analysis is the meshing. Since ANSYS software uses Finite Element Analysis method for solving the equation. In this method object or geometry under analysis is divided into number of small elements. Junction of elements is called as nodes. If we multiply number of nodes into number of elements then we get number of equations. ANSYS software solves the number of partial differential equation at each node and integrate the result of all equation to get final result. While meshing we have selected optimum element size which will give more accuracy and mimimum processing time. Once all the input parameters are given next step is solver. In solver you have to give inputs like equivalent stress, total deformation etc. which are reuired for your application to analyse. Once the ANSYS displays the results you have to to the post-processing. In postprocessing you compare your results with permissible values and if your results exceeds the allowable values you have to change certain parameters either related to the geometry or material. In structural analysis of tie rod we have applied tensile load of $8106 \mathrm{~N}$. we have given fixed support to the ball joint of the tie rod to find out equivalent or von- mises stresses generated in the tie rod and total deformation in the tie rod. The obtained stress and deformation values are compared with the permissible values to find out whether the design is safe of not.

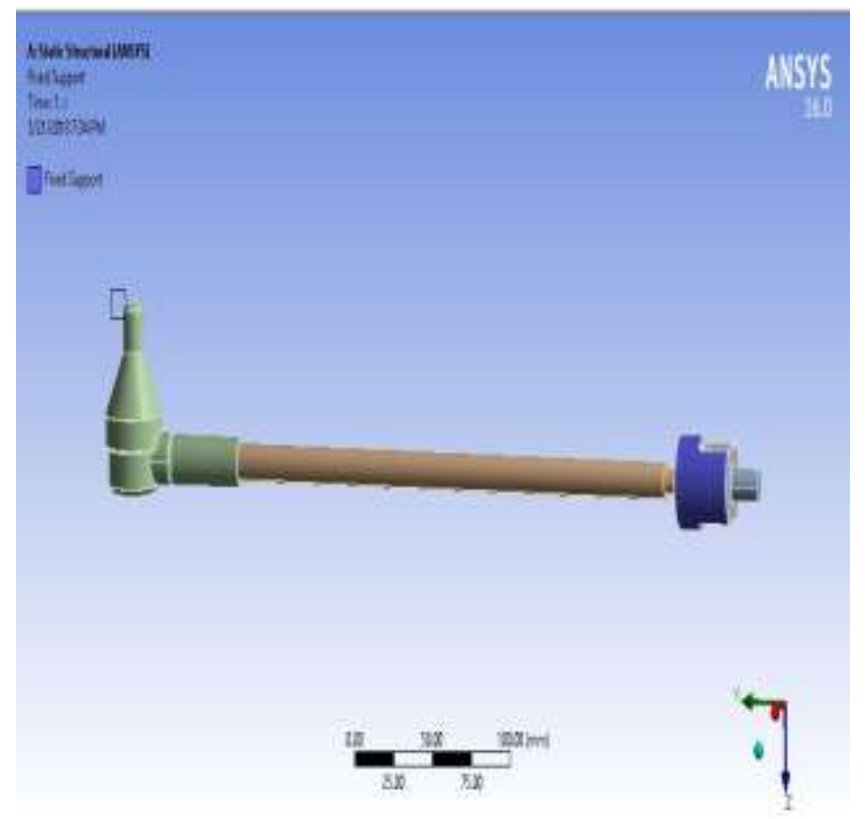

Fig 2: Fixed support at the ball joint

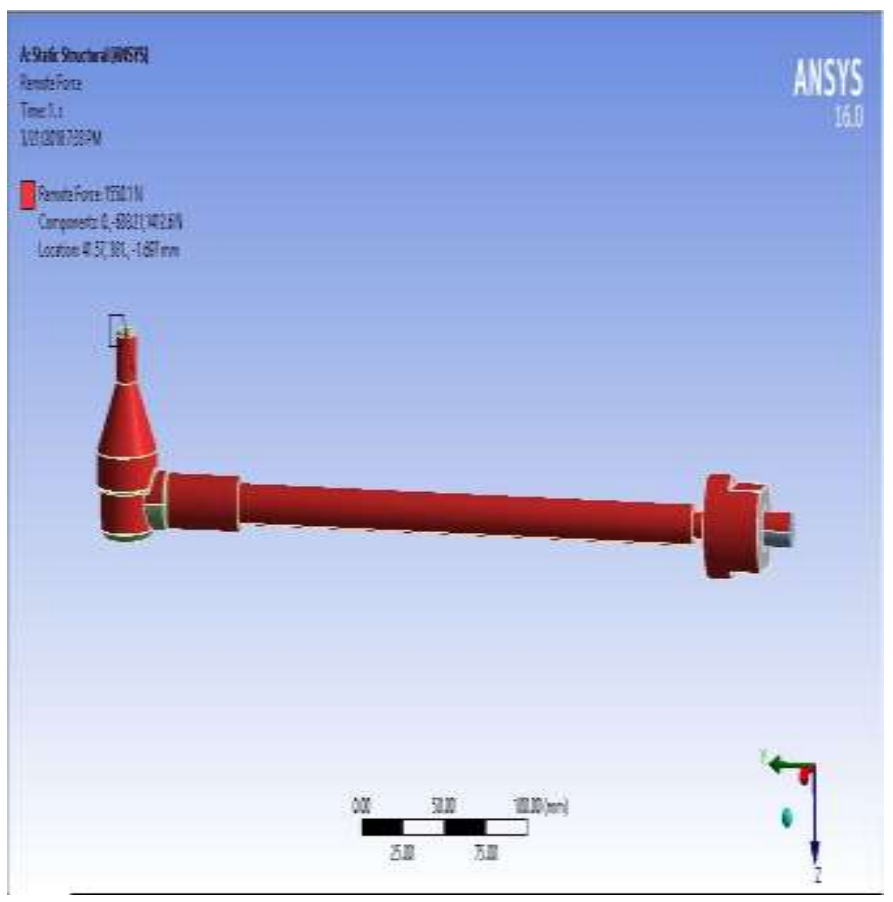

Fig 3: Tensile force on tie $\operatorname{rod}=8106 \mathrm{~N}$

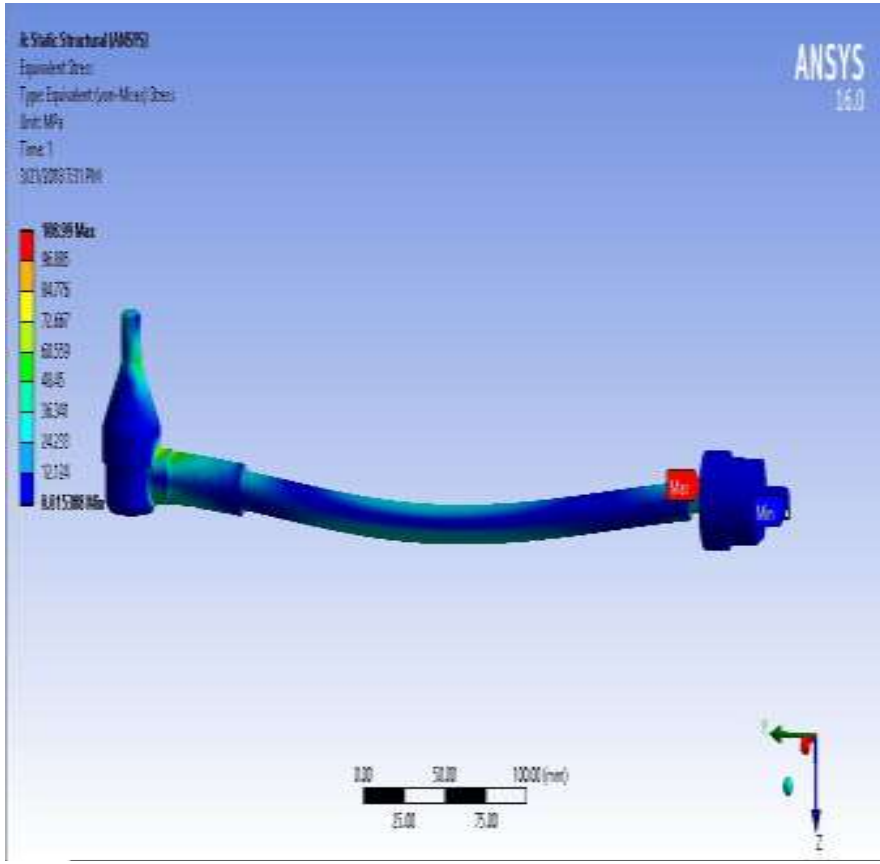

Fig 4: Equivalent (VON-MISES) Stress = 108.99 $\mathrm{MPa}$ 


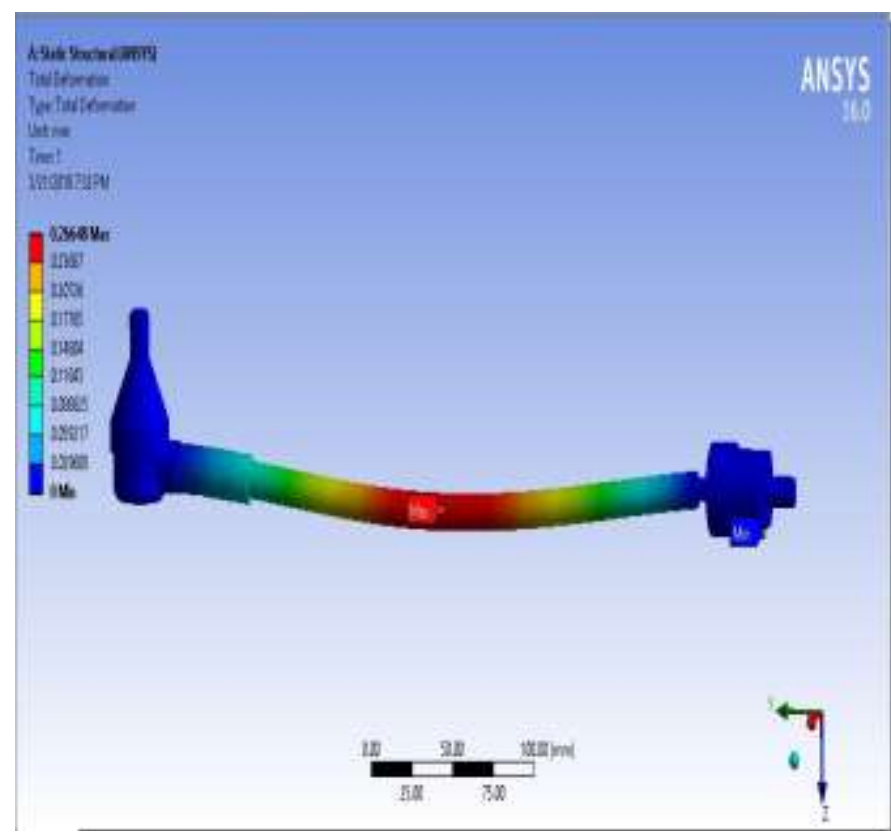

Fig 5: Total Deformation $=0.26648 \mathrm{~mm}$

\section{RESULT AND CONCLUSION}

Equivalent stress developed on tie rod is equal to 108.99 Mpa. To calculate whether this developed stress is within the safe limit we have to compare it with the maximum permissible stress.

Maximum permissible stress $=\frac{\text { maximum tensile stress }}{\text { factor of safety }}$.

$$
\text { I.e. } \max \text { permissible stress }=\frac{632}{5}
$$

Therefore $\max$ permissible stress $=126.4 \mathrm{Mpa}$

To calculate maximum permissible deformation

Max. Permissible deformation $=\frac{\text { maximum permissible stress }}{\text { modul us of elasticity }} *$ length of tie rod

Modulus of elasticity $=100590 \mathrm{Mpa}$

Maximum permissible stress $=126.4 \mathrm{Mpa}$

Length of tie rod $=460 \mathrm{~mm}$

From the above equation we get deformation $=0.5780 \mathrm{~mm}$

Table 3: Comparison of ANSYS results with maximum permissible value

\begin{tabular}{|l|l|l|l|}
\hline $\begin{array}{l}\text { Sr } \\
\text { no. }\end{array}$ & Type & $\begin{array}{l}\text { ANSYS } \\
\text { result }\end{array}$ & $\begin{array}{l}\text { Maximum } \\
\text { Permissible } \\
\text { value }\end{array}$ \\
\hline 1 & $\begin{array}{l}\text { Equivalent } \\
\text { stress }\end{array}$ & $108.88 \mathrm{Mpa}$ & $126.4 \mathrm{Mpa}$ \\
\hline 2 & $\begin{array}{l}\text { Total } \\
\text { deformation }\end{array}$ & $0.26648 \mathrm{~mm}$ & $0.5780 \mathrm{~mm}$ \\
\hline
\end{tabular}

As von mises stress (equivalent) < max permissible stress Therefore Design of tie rod is safe.

\section{REFERENCES}

[1] William F. Milliken, Douglas L. Milliken, Race car vehicle dynamics page 665-726

[2] Daniel Gay, Suong V. Hoa, Stephan W. Tsai (2003), Composite material Design and Application page 39$62,78-121$

[3] Suong V. Hoa Principles of manufacturing of composite materials page 13-40

[4] Autor K. Kaw, Mechanics of composite materials, second edition

[5] V.B.Bhandari, (1994) Design of Machine Elements, third edition page 334, 573-677

[6] Steven Fox, 'Cockpit Control Forces or How Robust Do Driver Control Really Needs To Be’ July 2010

\section{BIOGRAPHIES}

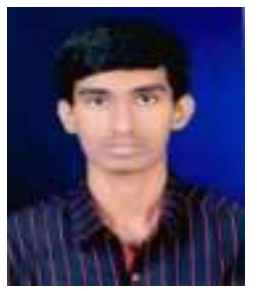

Omkar Diliprao Suryavanshi, Student at Mechanical Engineering Department, Vishwakarma Institute of Technology, Pune. Member of Steering Subsystem of BAJA SAE team ENDURANCE RACING. 